\title{
Environmental Pollution: Health Effects and Operational Implications for Pollutants Removal
}

\author{
Roya Kelishadi \\ Faculty of Medicine and Child Health Promotion Research Center, Isfahan University of Medical Sciences, Isfahan 81676-36954, Iran \\ Correspondence should be addressed to Roya Kelishadi, kelishadi@med.mui.ac.ir \\ Received 4 March 2012; Accepted 4 March 2012 \\ Copyright ( 12012 Roya Kelishadi. This is an open access article distributed under the Creative Commons Attribution License, \\ which permits unrestricted use, distribution, and reproduction in any medium, provided the original work is properly cited.
}

Environmental pollution is reaching worrying proportions worldwide. Urbanization and industrialization along with economic development have led to increase in energy consumption and waste discharges. The global environmental pollution, including greenhouse gas emissions and acid deposition, as well as water pollution and waste management is considered as international public health problems, which should be investigated from multiple perspectives including social, economic, legislation, and environmental engineering systems, as well as lifestyle habits helping health promotion and strengthening environmental systems to resist contamination [1-3].

Environmental pollutants have various adverse health effects from early life some of the most important harmful effects are perinatal disorders, infant mortality, respiratory disorders, allergy, malignancies, cardiovascular disorders, increase in stress oxidative, endothelial dysfunction, mental disorders, and various other harmful effects $[4,5]$. Though, short-term effects of environmental pollutants are usually highlighted, wide range of hazards of air pollution from early life and their possible implication on chronic non-communicable diseases of adulthood should be underscored. $\mathrm{Nu}$ merous studies have exposed that environmental particulate exposure has been linked to increased risk of morbidity and mortality from many diseases, organ disturbances, cancers, and other chronic diseases $[6,7]$. Therefore it is time to take action and control the pollution. Otherwise, the waste products from consumption, heating, agriculture, mining, manufacturing, transportation, and other human activities will degrade the environment.

Based on the strength of the scientific knowledge regarding the adverse health effects of environmental pollution and the magnitude of their public health impact, different kinds of interventions should be taken into account. In addition to industrial aspects, the public awareness should be increased in this regard. Likewise, health professionals have an exclusive competency to help for prevention and reduction of the harmful effects of environmental factors, this capacity should be underscored in their usual practice.

This special issue is dedicated to increasing the depth of research across all areas of health effects of pollutants in air, water, and soil environments, as well as new techniques for their measurement and removal. The goal of the special issue is to familiarize the readership of the Journal of Environmental and Public Health with the potential for different aspects of environmental pollution. We expect this special issue would appeal to researchers, public health practitioners, and policymakers.

Roya Kelishadi

\section{References}

[1] N. T. Loux, Y. S. Su, and S. M. Hassan, "Issues in assessing environmental exposures to manufactured nanomaterials," International Journal of Environmental Research and Public Health, vol. 8, no. 9, pp. 3562-3578, 2011.

[2] T. Abbasi and S. A. Abbasi, "Water quality indices based on bioassessment: the biotic indices," Journal of Water and Health, vol. 9, no. 2, pp. 330-348, 2011.

[3] H. Yuan, "A model for evaluating the social performance ofconstructionwaste management," Waste Management. In press.

[4] R. Kelishadi, N. Mirghaffari, P. Poursafa, and S. S. Gidding, "Lifestyle and environmental factors associated with inflammation, oxidative stress and insulin resistance in children," Atherosclerosis, vol. 203, no. 1, pp. 311-319, 2009. 
[5] R. Kelishadi and P. Poursafa, "Air pollution and non-respiratory health hazards for children," Archives of Medical Science, vol. 6, no. 4, pp. 483-495, 2010.

[6] M. Kargarfard, P. Poursafa, S. Rezanejad, and F. Mousavinasab, "Effects of exercise in polluted air on the aerobic power, serum lactate level and cell blood count of active individuals," International Journal of Preventive Medicine, vol. 2, no. 3, pp. 145-150, 2011.

[7] P. F. Coogan, L. F. White, M. Jerrett et al., "Air pollution and incidence of hypertension and diabetes mellitus in black women living in los angeles," Circulation, vol. 125, no. 6, pp. 767$772,2012$. 


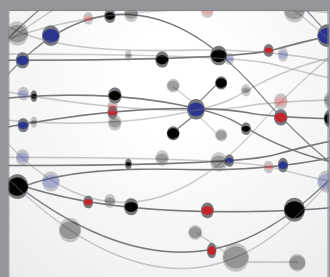

The Scientific World Journal
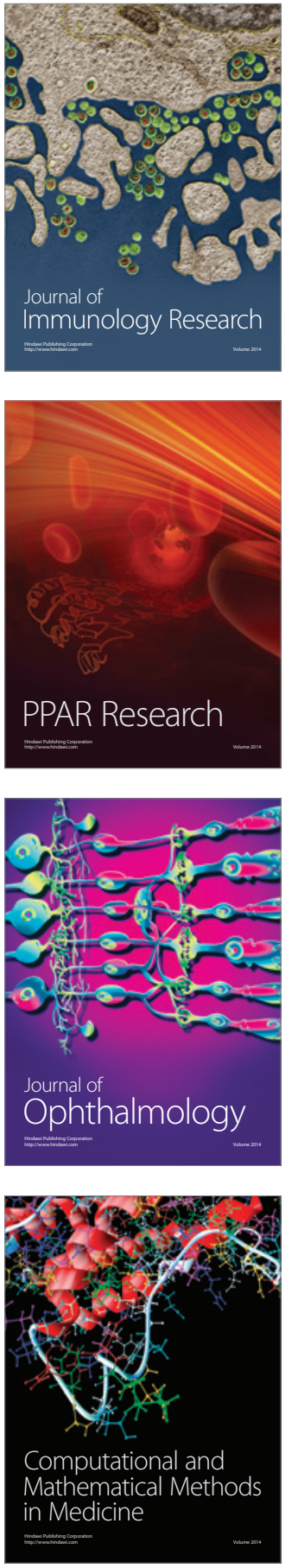

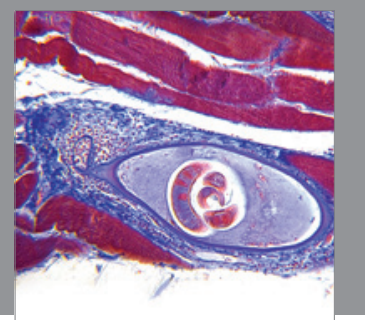

Gastroenterology

Research and Practice
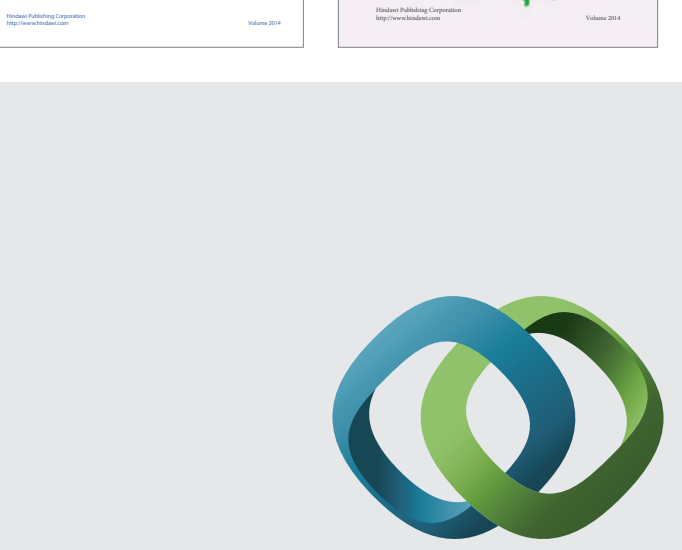

\section{Hindawi}

Submit your manuscripts at

http://www.hindawi.com
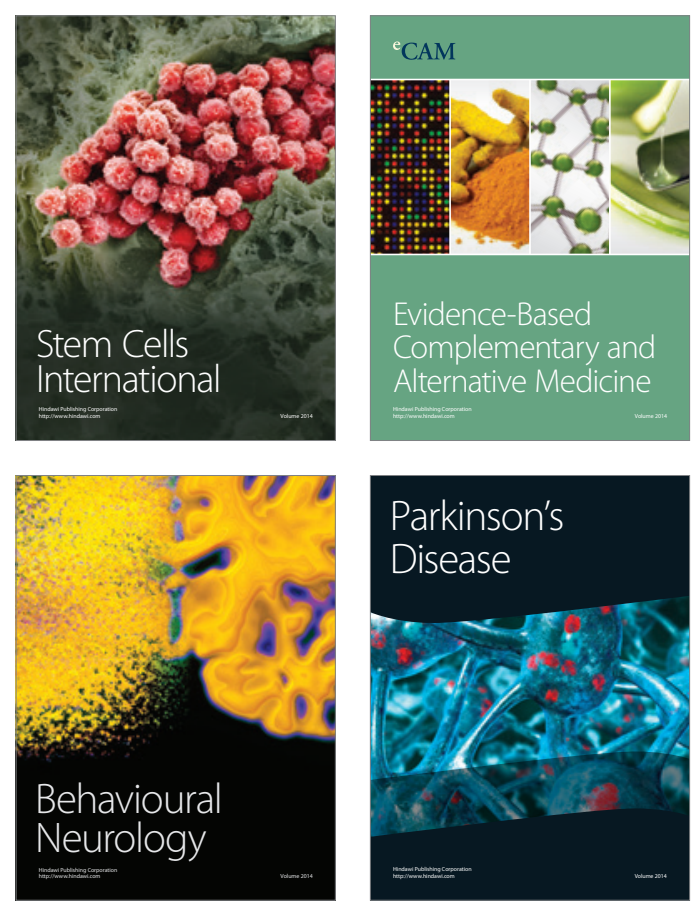

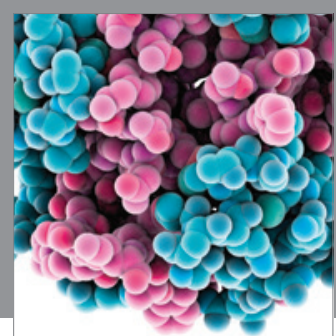

Journal of
Diabetes Research

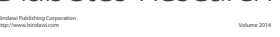

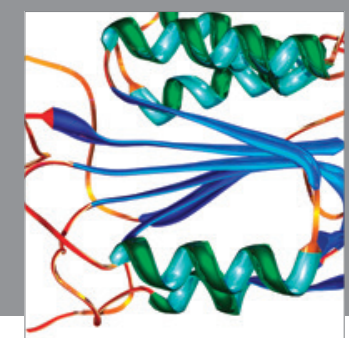

Disease Markers
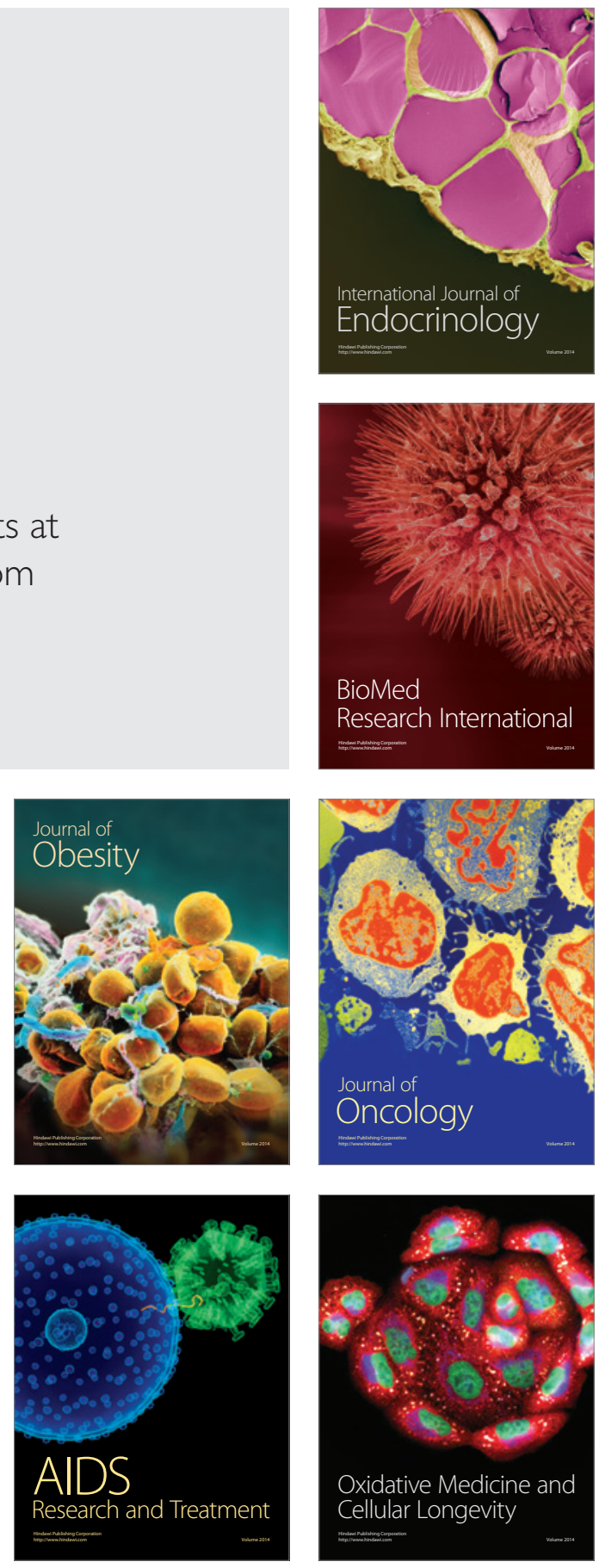